\title{
Mídia-Educação: recursos midiáticos e a mediação do conhecimento.
}

Carla Silvanira Bohn, UFSC/(PPGEGC), carlabws@gmail.com

Fabrício Raupp, UFSC/(PPGEGC), fabricioraupp@ hotmail.com

Marcio Luis Bess, UFSC/(PPGDN), marciobess@ hotmail.com

Silvio Serafim da Luz Filho, UFSC/(PPGEGC), silvioserafim@bol.com.br

Resumo: As novas tecnologias da informação e comunicação promovem uma nova leitura no panorama educacional, onde a utilização adequada dos recursos midiáticos torna-se forte aliado no processo ensino-aprendizagem. Mediar esse processo, atualmente defendido pela literatura, é fundamentalmente importante para a construção do conhecimento. Este artigo, busca a partir da pesquisa exploratória, apresentar uma discussão sobre a mídia-educação e os processos de ensino e aprendizagem, perpassando pelos conceitos do conhecimento, aprendizagem interativa - e-learning e teoria do flow - e aprendizagem mediatizada, relacionando os mesmos a teoria cognitiva. Numa perspectiva cognitivista, um ambiente virtualmente educativo pode impulsionar a capacidade de compreensão e interiorização do conhecimento, desenvolvendo a real habilidade do "aprender a aprender".

Palavras-chave: Mídia-educação. Processo de ensino aprendizagem. Aprendizagem Interativa. Teoria Cognitiva.

\section{Media-education: media resources and the knowledge mediation}

\begin{abstract}
The new technologies of information and communication promote a new reading in educational landscape, where the appropriate use of media resources becomes a strong ally in the teaching-learning process. Mediate this process, currently advocated by the literature is fundamentally important to the construction of knowledge. This article seeks from the exploratory research, present a discussion on media education and the teaching and learning, going through the concepts of knowledge, interactive learning - e-learning and theory of flow - and mediated learning, relating them cognitive theory. In a cognitive perspective, a virtual environment education can boost the capacity for understanding and internalization of knowledge by developing a real skill of "learning to learn."
\end{abstract}

Keywords: Media-education. Teaching learning process. Learning Interactive. Cognitive theory.

\section{INTRODUÇÃO}

Este artigo busca a partir dos pressupostos teóricos e da mídia-educação, uma reflexão no campo educacional, rompendo paradigmas até então praticados, proporcionando espaços integrados de conhecimento tácito e exteriorizados, linguagem e significado. (SCHMID, 1998).

Na tentativa de elaborar modelos explicativos que mais se aproximem dos aspectos gerais da cognição, surgiu, então a necessidade de relacionar a mesma com a aprendizagem interativa, como por exemplo, e-learning.

Experiências como o e-learning (experiential learning), descrevem o aprendizado através da experiência prática, esta concepção de aprendizado é muito coerente com os jogos eletrônicos onde o aprendiz pode experimentar e construir seu conhecimento através da ação e 
reflexão (KIILI, 2005), porém, por ser considerada uma prática recente exige que os princípios educativos do ensino tradicional sejam ampliados para poder se adaptar as rápidas mudanças tecnológicas.

A atração e fascínio que os games exercem nas crianças e adolescentes, despertam a necessidade de estudo, visto que, por passarem horas em frente ao computador, torna-se claro encontrar uma maneira de "casar" aquilo que instiga e prende a atenção, com o que a educação se propõe a executar, "quaisquer meios de comunicação ou mídia são inseparáveis das formas de socialização e cultura que são capazes de criar, de modo que o advento de cada novo meio de comunicação traz consigo um ciclo cultural que lhe é próprio" ( SANTANELA, apud MOITA, 2006).

Compreender este contexto e encontrar meios que promovam a disseminação do conhecimento através da mídia, adentra ao campo cognitivo como facilitador do processo de ensino e aprendizagem, pois busca associar a criatividade e a imaginação com a racionalidade e a lógica, mediatizando, estimulando e potencializando a capacidade cerebral, construindo efetivamente a aprendizagem.

\section{APRENDIZAGEM MEDIATIZADA E INTERATIVIDADE}

Aliando o conteúdo das inovações da atualidade e a necessidade da inserção de práticas que potencializam o processo de ensino e aprendizagem e estejam efetivamente condizentes com as expectativas do público imerso às Novas Tecnologias de Informação, abre-se um novo e vasto campo de pesquisa, que diz respeito aos "modos de aprendizagem mediatizada" (BELLONI, 2005) que rediscute os processos de aprendizagem sob uma ótica mais abrangente e até mesmo flexível no que diz respeito aos métodos aplicados.

Na mídia-educação, a construção de métodos, considerando os componentes de uma nova pedagogia, está voltada "a utilização cada vez maior das tecnologias de produção, que estocam a transmissão de informações, por um lado, e, por outro, o redimensionam o papel do professor" (BELLONI, 2005).

Considerando a escola uma organização com o compromisso social de educar para a cidadania, nos remete a pensar em como uma organização será o agente facilitador e/ou potencializador deste processo, porque em função de "as organizações, enquanto meio social, no qual os indivíduos estão inseridos, exercem uma função estimuladora ou bloqueadora do desenvolvimento cognitivo" Aguiar (2006). Evidencia-se neste aspecto a necessidade de buscar na educação, focando as mídias, condições para construir um facilitador à prática, que contribua atraindo o aluno de maneira que não interrompa seu ciclo evolutivo criativo, seja perspicaz e o estimule-o a reflexão. Construir um instrumento na perspectiva para o mundo contemporâneo, que não mais é apenas físico, mas sim "da cidade virtual, da sociedade virtual, misturada e integrada com o real", (FANTIN, 2006) é desafiador, mas por ser assim, instigante e motivador.

O fato de as Novas Tecnologias de Informação promover a crescente busca por criação/inovação direciona a prática educacional diferenciada e axiomática no sentido que: necessita de uma infra-estrutura adequada; utilize dos novos meios nos processos de ensino e aprendizagem; postule uma gestão construtivista; invista na capacidade do aluno de adquirir sua própria educação; esteja pautada em qualidade e não em previsão quantitativa; crie um ambiente de ensino interativo ampliando a interação do docente; e ainda, questione as convicções pedagógicas no que diz respeito à visão estereotipada sobre os alunos e o processo de aprendizagem (MC CLINTOCK apud SANCHO, 2006).

Considerando que a recente pesquisa focada em jogos eletrônicos vem apontando aspectos positivos e relevantes à prática pedagógica, como a associação de conceitos importantes: aprendizado, diversão e interatividade, demonstram que a fusão da mídia com 
foco na construção cognitiva do conhecimento é evidentemente positiva. Teorias como de Kolb (1984) na experiência prática - e-learning - e na teoria de Flow - teoria do fluxo - de CsiKszentmihalyi, demonstram o aprendizado como um processo holístico, prazeroso, envolvendo todas as atividades do ser humano, o pensamento, o sentimento, a percepção e o comportamento.

A teoria de aprendizagem de David Kolb (1984) apresenta quatro distintos estilos de aprendizagem, os quais são pautados em um círculo de aprendizagem de quatros estágios, e a partir de sua análise, demonstra um caminho para entender os estilos individuais de aprendizagem diferente das pessoas e também uma explanação de um círculo de aprendizagem experiencial que se aplica a todos nós.

Kolb (1984) inclui esse 'círculo de aprendizagem' como um princípio central de sua teoria de aprendizagem experiencial (e-learning), tipicamente expressa como círculo de aprendizagem de quatro estágios, em que 'experiências imediatas ou concretas' fornece uma base para 'observações e reflexões'. Tais 'observações e reflexões' são assimiladas e destiladas em 'conceitos abstratos', produzindo novas implicações para a ação que pode ser 'ativamente testada', a qual, por sua vez, cria novas experiências.

Kolb diz que idealmente este processo representa um círculo de aprendizagem ou espiral onde o aprendiz 'toca todas as bases', isto é, um círculo de experiência, reflexão, pensamento e atividade. Experiências concretas ou imediatas conduzem a observações e reflexões. Essas reflexões são então assimiladas (absorvidas e traduzidas) em conceitos abstratos com implicações para a ação, que a pessoa pode ativamente testar e com as quais experimentar o que, por sua vez, habilita a criação de novas experiências.

O modelo de Kolb, portanto, trabalha em dois níveis - um círculo de quatro estágios: 1. Experiência Concreta; 2. Observação Reflexiva; 3. Conceituação Abstrata; 4. Experimentação Ativa - e uma definição de quatro tipos de estilos de aprendizagem para os quais usa os termos: divergência; assimilação, convergência e acomodação. (Ver fig. 01)

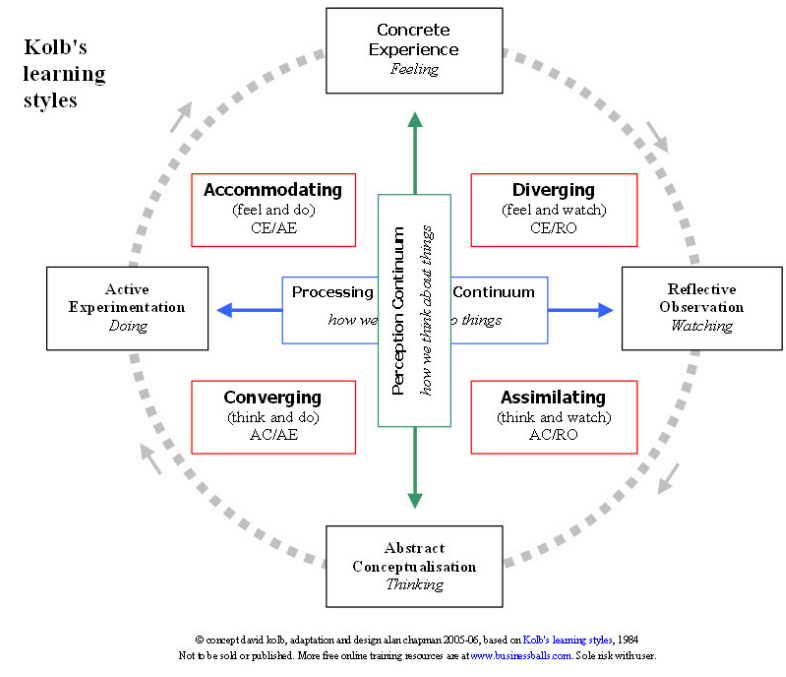

Figura 01: Learning styles - Adaptação do texto KOLB (1984 p.141).

Neste sentido, do ponto de vista do aprendizado, a escola que valoriza as experiências vivenciadas para um aprendizado mais completo, considerando jogo eletrônico uma fonte de experiências em potencial pode desfrutar de resultados surpreendentes (KOLB, 1984).

A teoria do Flow, proposta pelo psicólogo norte-americano de origem húngara e professor da Universidade de Chicago Mihaly Csikszentmihalyi, diz respeito à experiência subjetiva, e no que se refere literalmente a palavra 'flow', em uma tradução livre, significa 'fluxo' ou 'estado de imersão'. Csikszentmihalyi (1990) aborda o estado mental de um 
indivíduo, onde engajado em uma atividade qualquer se encontra completamente focado, envolvido e energizado, caracterizando como: prontidão, foco, meta, feedback, sensação e experiência subjetiva. Este estado de 'imersão' defendido pelo autor, pode ser encontrado no jogador de game, o que instiga a correlação de sua teoria como âncora à busca pretendida nesta pesquisa.

Adentrando ao universo dos games, a literatura aponta que, "ironicamente, jogos comuns produzem melhores resultados à pedagogia que a maioria dos jogos educativos" (COSTA, 2008), remetendo neste aspecto a um 're-pensar' nos métodos e práticas aplicadas no cotidiano docente.

Na busca por inovação, Belloni (2005) diz que o papel do professor é fundamental neste processo, tanto por assegurar e incentivar, quanto por estimular entender a autodidaxia, adequando métodos e estratégias de ensino, atuando como mediador, traduzindo e codificando as mensagens pedagógicas sob diversas formas.

Nesta discussão a autora esclarece que para a escola acompanhar esse novo desafio, é preciso que formule a:

"mediatização do processo de ensino/aprendizagem aproveitando ao máximo as potencialidades comunicacionais e pedagógicas dos recursos técnicos: criação de materiais e estratégias, metodologias; formação de educadores (professores, comunicadores, produtores, tutores); produção de conhecimento. (BELLONI, 2005, p.09).

E acrescenta ainda que, faz-se necessário analisar e apontar novas temáticas de pesquisa, em função dos novos fenômenos no campo da educação: "a mediatização da comunicação e da educação e os novos papéis e características dos atores principais deste campo: o professor coletivo e o estudante autônomo." (BELLONI, 2005).

\section{APRENDIZAGEM COMO PROCESSO DE CONHECIMENTO}

A trajetória da Sociedade Industrial para a Sociedade da Informação e do Conhecimento desponta um novo conceito: knowledge organizations ou organizações do conhecimento, mostrando que, segundo o seu próprio criador, Sveiby (1998) "Para enxergar a organização do conhecimento, os gerentes devem procurar ver suas organizações como se elas consistissem de estruturas de conhecimento e não de capital".

Neste sentido, faz-se necessário inicialmente compreender o próprio conceito do termo conhecimento:

Peter Drucker (2002) define que,

"O conhecimento, como o consideramos hoje, é comprovado por meio da ação. O que atualmente significa conhecimento é a informação que se efetiva em ação, a informação focalizada nos resultados. Esses resultados são vistos fora da pessoa - na sociedade e na economia, ou no progresso do conhecimento em si”. (2002 p. 32)

Davenport e Prusak (1998) definem conhecimento como:

“... uma mistura fluida de experiência condensada, valores, informação contextual e insight experimentado, a qual proporciona uma estrutura para a avaliação e incorporação de novas experiências e informações. Ele tem origem e é aplicado na mente dos conhecedores. Nas organizações, ele costuma ser embutido não só em documentos ou repositórios, mas também em rotinas, processos, práticas e normas organizacionais". (1998 p. 6)

Segundo Nonaka e Takeuchi (1997, p.1), por criação do conhecimento organizacional, entende-se a capacidade de uma empresa criar novo conhecimento, difundi-lo na organização 
como um todo e incorporá-lo a produtos, serviços e sistemas [...] o conhecimento desempenha um papel importante na conquista da vantagem competitiva.

Os autores Nonaka \& Takeuchi (1997, p.23) revelam que,

\begin{abstract}
"Para que possa ser comunicado e compartilhado dentro da organização, o conhecimento tácito tem que ser convertido em palavras ou números que qualquer um possa compreender, e é exatamente durante esse processo de conversão de tácito para explícito que o conhecimento organizacional é criado (...) entender o conhecimento tácito representa transformar a organização em um organismo vivo, no lugar de apenas uma máquina de processamento de informações".
\end{abstract}

Esses autores destacam quatro processos de conversão do conhecimento: Explicito para o Explícito = Combinação; Explícito para o Tácito= Internalização; Tácito para o Tácito = Socialização; Tácito para o Explícito Externalização. (Ver fig. 02)
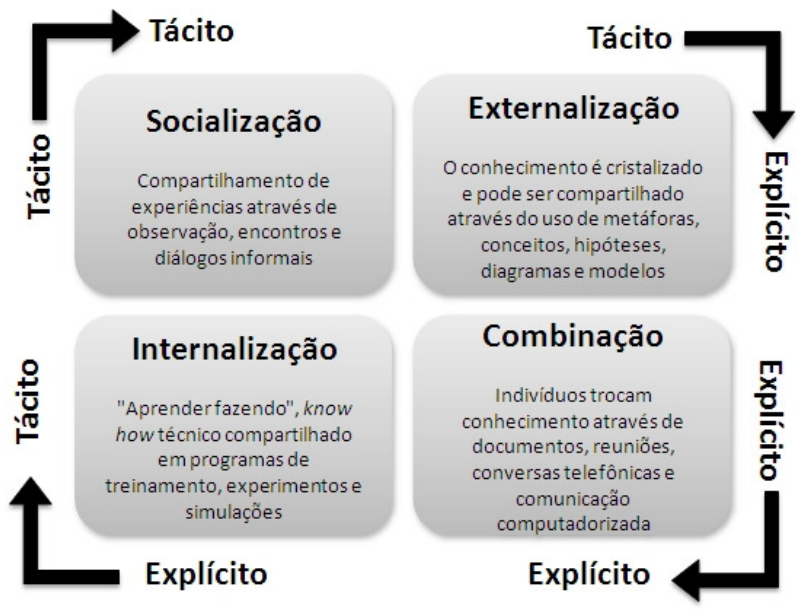

Figura 02: Modelo SECI Adaptação do texto NONAKA\&TAKEUCHI (2008 p. 24)

Nesse contexto o processo de aprendizagem nas organizações está intimamente ligado à cognição, sendo essa individual, mas que gera nas organizações um processo de aprendizagem coletiva.

Schmid (1998) destaca que "o fundamento do conhecimento é a informação - a forma codificada de exteriorização de conhecimento". E acrescenta que a "TIC é o capacitador básico da eficiente gestão da informação".

\title{
4 INTER-RELAÇÃO: MÍDIA-EDUCAÇÃO - APRENDIZAGEM INTERATIVIDADE
}

Segundo Lave e Wenger (1991), a aprendizagem é uma função da atividade, do contexto e da cultura na qual ela ocorre (isto é, ela é situada). Esta afirmação contrasta com a maioria das atividades de aprendizagem realizadas em classe, para aquisição de conhecimentos, que são abstratas e fora de contexto.

Interação social é uma componente da aprendizagem situada, alunos são envolvidos em sala para incorporar algumas crenças e comportamentos a serem adquiridos.

Alguns pesquisadores têm desenvolvido a teoria da aprendizagem, como Brown, Collins e Duguid (1989), que enfatizaram a idéia da aprendizagem cognitiva. Segundo estes autores, a aprendizagem cognitiva apóia o processo de aquisição de conhecimentos, em uma 
determinada área, permitindo que os alunos possam adquirir, desenvolver e utilizar ferramentas cognitivas no domínio de uma atividade autêntica.

A aprendizagem, dentro e fora escola, é viabilizada por meio da interação social entre as pessoas, assim, construção social do conhecimento é fomentada pela troca de informações. É pela aprendizagem que se constroem conhecimentos. Ela pode ser aplicada no contexto de escolas em atividades centradas na capacidade de solucionar problemas, pois vai exigir que os alunos construam um conhecimento novo para solucionar o problema ou solucionem o problema através de métodos conhecidos.

Pode-se entender educação como um processo permanente na vida das pessoas, com suas diferentes práticas e atividades no contexto social (CLAUSSE, 1969; FREIRE, 1997). Freire (1997) afirma que são as reflexões sobre o ser humano que os faz entender educação como prática permanente. Segundo Piaget $(1985$, p. 154) "educar é adaptar o indivíduo ao meio social ambiente." $\mathrm{Na}$ frase anterior o autor refere-se a modificar a constituição psicológica do sujeito de acordo com a sua realidade social.

De acordo com Guareschi (2005) educação deve ser entendida como algo mais amplo, estando ela presente em diferentes momentos da vida social das pessoas. "A educação é um ato de amor, por isso, um ato de coragem. Não pode temer o debate, a análise da realidade. Não pode fugir à discussão criadora, sob a pena de ser uma farsa." (FREIRE, 1983, p. 96). Trabalhar com educação é doar um pouco de si para o outro.

Pelo dinamismo e exigências da sociedade a pessoa deve prosseguir com educação pela vida inteira, pois se isso não acontecer ela será ultrapassada pelo outro que está nesse processo de educação transformação (CLAUSSE, 1969). É pela educação que o sujeito conquista a sua autonomia, consegue libertar-se do outro e vai buscar o conhecimento (FREIRE, 2006). O educador possui um papel importante na formação das pessoas, pois ele pode estimular e administrar a curiosidade por aprender (DIMENSTEIN, 1999, apud NEVES et al., 2007).

Segundo Pretto e Pinto (2006, p. 23) "pode-se afirmar que a educação, hoje em dia, deve, idealmente, preparar as pessoas para a vida, cidadania e trabalho." Contribuir com a formação social do sujeito, com as práticas do cotidiano das pessoas (FREIRE, 1997). A educação possibilita a formação de seres humanos conscientes, críticos, livres e responsáveis (FREIRE, 1983; GUARESCHI, 2005).

Gadotti (1997) ressalta que, educação é muito mais do que instrução, do que treinamento ou a simples repetição. O querer aprender é eminentemente transformador, deve se enraizar na cultura dos povos, pois a partir dele as pessoas tornam-se livres. A modernidade se caracteriza pela superficialidade das relações e pelo consumo imediato. O aprender é um processo em longo prazo e precisa combater o imediatismo, o consumismo, se quiser contribuir para a transformação de uma sociedade.

Através da aprendizagem as pessoas podem mudar suas habilidades, o modo de fazer e de conhecer as diferentes informações disponíveis a ela. A interação com experiências anteriores contribui para as novas transformações e a aprendizagem em si. A aprendizagem depende das estratégias utilizadas para aprender, ou seja, do plano de aprendizagem formulado para atingir determinado efeito, de acordo com o método que o sujeito estabelece para aprender ele obterá um resultado (CARRETEIRO, 2003).

Assim o processo de informação também está diretamente ligado à aprendizagem, pois ambos possuem uma relação direta com a cognição. São inúmeras as formas de aprender e cada pessoa é única nesse processo. Pode-se aprender lendo, ouvindo, errando, na prática, vivenciando e observando entre outras.

“... a conjugação de situações de aprendizagem que podem propiciar a transformação do conhecimento em competência, essa transformação, só acontece em um contexto profissional específico, pois a realização da 
competência deverá não apenas agregar valor ao indivíduo, mas também a organização.” (FLEURY \& FLEURY, 2007 p. 41).

No âmbito educacional, é relevante acrescentar, que segundo Aguilar (2003) "conhecimento é nada, ou quase nada se não soubermos usá-lo adequadamente, apropriadamente e corretamente nas mais variadas situações da vida pessoal e profissional".

Na prática pedagógica, Kolb (1984) contribui com um modelo de aprendizagem baseada em três modelos, de Lewin, Dewey e Piaget, e suas principais características são:

a) aprendizado como processo: onde nega a concepção - behaviorista - de que as idéias são fixas e imutáveis e o que existe são as combinações entre as idéias;

b) aprendizado contínuo: baseado em experiência, coloca que o conhecimento é sempre testado e aperfeiçoado pela experiência prévia, concepção de que o aluno está sempre passando por uma reeducação;

c) necessidade de solução de conflitos: a forma como as habilidades conflitantes são utilizadas pelo aprendiz durante o aprendizado definem a qualidade do aprendizado;

d) processo holístico: interpreta o aprendizado envolvendo todas as atividades do ser humano, não apenas o funcionamento cognitivo, mas o pensamento, sentimento, percepção e comportamento;

e) troca entre o indivíduo e o ambiente: relação entre a experiência subjetiva e a experiência ambiental, possibilidade de o indivíduo agir sobre o ambiente, modificando-o de maneira objetiva;

f) aprendizado como processo criador de conhecimento: e-learning, conhecimento como resultado da aprendizagem, consiste em uma interação entre a experiência pessoal, cultural e subjetiva, com a experiência com o "conhecimento social" (social knowledge). (KOLB, 1984)

Modelo este que focando as transformações causadas pela revolução tecnológica, podem auxiliar na incorporação da mídia-educação à prática pedagógica com o propósito formar continuamente indivíduos éticos, construtores críticos da sociedade, que utilizem mídia na perspectiva da Tecnologia Educacional, sem distanciar da condição humana, com princípios voltados para os valores humanos. (FREIRE, 2008)

A inserção de um artefato como referência pedagógica de potencializador do ensino, como o jogo eletrônico, por ser recente, gera certa resistência e afronta os métodos tradicionais de ensino. Mas a idéia de unir os jogos eletrônicos à educação perpassa por três conceitos importantes: aprendizado, diversão e interatividade, e requer no coletivo um minucioso trabalho investigativo e incentivador, porque não é possível prever as reações e/ou aceitações no cotidiano social, visto que, as intenções podem não estar voltadas aos interesses de toda uma comunidade, ao qual muitas vezes desconhece os benefícios dos recursos tecnológicos.

A intervenção da escola num plano tecnológico-pedagógico pode promover uma releitura das relações inter-pessoais e uma interpretação mais coerente quanto às informações e valores transmitidos via tecnologia.

Levy (2001) interpreta a intervenção da tecnologia à cultura social como "cibercultura" e acrescenta que, o ciberespaço será o principal ponto de apoio de um processo ininterrupto de aprendizagem e de ensino da sociedade por si mesma [...] todas as instituições humanas irão se integrar e convergir para uma inteligência coletiva sempre capaz de produzir e explorar novas formas. (LEVY, 2001)

O Ciberespaço, segundo Levy, é o espaço de comunicação aberto pela interconexão mundial dos computadores e das memórias dos computadores [...] tem a vocação de colocar em sinergia e interfacear todos os dispositivos de criação de informação, de gravação, de comunicação e de simulação. (Levy, 1999, p.92-93) 
Se o advento da era digital impulsionou e permitiu maior velocidade e agilidade na comunicação e tendo em vista que é essencial para a Era do Conhecimento, o campo educacional deve prover de mecanismos que associem a dinâmica de seu entorno com suas práticas diárias, para que no cerne da aprendizagem seu público alvo, que vem sedento pelo conhecimento, não se depare com uma realidade completamente aquém da capacidade cognitiva.

\section{CONSIDERAÇÕES FINAIS}

Entre os desafios diários e a necessidade de mudança, é de fundamental importância pensar em ações conjuntas, sincronizar a prática docente como potencializador do processo criativo e cognitivo, mediar sua prática numa ótica de ação - inovação, através das mídias do conhecimento; aliar-se as TIC numa perspectiva de alavancagem e estímulo, tornando assim possível visualizar o ensino em sua excelência, socializando, externalizando, combinando e internalizando saberes.

Nesta ótica, podemos perceber que, numa perspectiva cognitivista, a utilização e implementação de um ambiente virtualmente educativo pode impulsionar a capacidade de compreensão e interiorização do conhecimento, desenvolvendo a real habilidade do "aprender a aprender".

A proposta apresentada neste trabalho foi de, fazer uma revisão da literatura, descrevendo aspectos relevantes e apresentando teorias que respaldam a mediação entre games, educação e aprendizagem, ao qual pode contribuir a releitura da prática pedagógica observando os novos fenômenos que o campo educacional apresenta.

No intuito de contribuir a ótica educacional, visto que o mesmo não consegue acompanhar o corrente crescimento e a velocidade que a sociedade do conhecimento impõe, e por conseguinte, possa ser referência como contribuição acadêmica e como prática bem sucedida na fusão Mídia-Educação, Mediatização e Interatividade , percebemos que o tema não se esgota aqui, e sim a pesquisa bibliográfica nos remete a identificação do quanto é vasto o campo do estudo que podem impulsionar ou potencializar o desenvolvimento do processo de aquisição de conhecimento.

\section{REFERÊNCIAS}

AGUIAR, M. A. F. Psicologia aplicada à administração: uma abordagem interdisciplinar. São Paulo: Editora Saraiva, 2006.

AGUILAR, M. A. Era do Conhecimento ou da competência? Abceducatio: a revista da educação, São Paulo, Criart Ltda., v. 4, n. 25, p. 10-11, jun. 2003.

ANGELONI, M. T. (org.) Organizações do Conhecimento: Infra-Estrutura, Pessoas e Tecnologia. 2. ed. São Paulo: Saraiva. 2008.

APPOLINÁRIO, F. Metodologia da Ciência: Filosofia e Prática da Pesquisa. São Paulo: Pioneira Thomson Learning, 2006.

BASTOS, A. V. B. A questão da cognição. IN. DAVEL, E \& VERGARA, S. C. (Org). Gestão com pessoas e subjetividade. São Paulo: Editora Atlas, 2007.

BELLONI, M. L. O que é Mídia-Educação. 2. ed. Campinas: Autores Associados (Coleção Polêmicas do Nosso Tempo), 2005.

BROWN, J. S.; COLLINS, A.; DUGUID, P. Situated cognition and the culture of learning. Educational Researcher, v. 18, n. 1, p. 32-42, Jan./Feb. 1989. 
CARRETEIRO, R. M. Psicologia da Aprendizagem: Aprender a Aprender. Psiclínica Psicologia Clínica. Lisboa, Portugal. Nov. 2003. Disponível em:

$<$ http://www.psiclinica.net/docs/texto2.pdf> Acesso em: 27 fev. 2010.

CLAUSSE, A. Iniciação às ciências da educação. Trad. Luiz Damasco Penna e J. B. Damasco Penna. São Paulo: Editora Nacional, 1969.

COSTA, L. D., COUTO, R., WILMER, C. O que os jogos de entretenimento têm que os jogos com fins pedagógicos não têm. In: Anais do 8 Congresso Brasileiro de Pesquisa e Desenvolvimento em Design. São Paulo - SP. Outubro de 2008.

CSIKSZENTMIHALYI, M. Flow: the psychology of optimal experience. United States of America, Harper \& Row Publishers, 1990.

DAVENPORT, T.; PRUSAK, L., Working knowledge - How organizations manage what they know; Boston: Harvard Business School Press, 1998. in: Amândio Evangelista; Antonio Donato; Fernando Carvalho; Humberto Neves. A Gestão Do Conhecimento Nas Organizações. Comportamento Organizacional. Portugal: Instituto Superior de Economia e Gestão. 2003.

DRUCKER, P. A Quarta Revolução da Informação. São Paulo: Exame. 1998. p.52-58.

FANTIN, M. Mídia-Educação: Conceitos, experiências, diálogos Brasil-Itália. Florianópolis: Cidade Futura, 2006.

FLEURY, M. T. L. \& OLIVIRA Jr, M. M, Aprendizagem e gestão do Conhecimento. In: FLEUTY, M. T. L.(coord.). As pessoas na organização. 9 ed. São Paulo: Editora Gente, 2002.

FREIRE, P. Educação como prática de liberdade. 14.ed. Rio de Janeiro: Paz e terra, 1983. Política e educação. 3. ed. Vol 23. São Paulo: Cortez, 1997. A educação na cidade. 7. ed. São Paulo: Cortez, 2006.

FREIRE, W. (org.). Tecnologia e Educação: As mídias na prática docente. Rio de Janeiro: Wak Editora. 2008.

GADOTTI, M. Lições de Freire, Ver. Faculdade de Educação v. 23, n. 1-2 Jan. /Dez., São Paulo, 1997.

GUARESCHI, P. A. Mídia, educação e cidadania: tudo o que você deve saber sobre a mídia. 2.ed. Petrópolis: Vozes, 2005.

KIILI, K. Digital Game-based learning: Towards an experimential gaming model. The Interner and Higher Education 8, p. 13-24 (2005) Disponível em:

$<$ http://scienciedirect.com/sience?_ob=Article>. Acesso em: 08/11/2010.

KOLB, D. Experimential Learning: Experience as The Source of Learning and Development. Prentice Hall, Englewood Cliffs, New Jersey, 1984.

LAVE, J., e WENGER, E. Situated Learning: Legitimate Peripheral Participation. Cambridge, UK: Cambridge University Press, 1991.

LEVY, P. A conexão Planetária: o mercado, o ciberespaço, a consciência. São Paulo: Editora 34, 2001.

Cibercultura. São Paulo: Ed. 34, 1999.

MATURANA, H. R.; VARELA, F. J. A Árvore do Conhecimento: as bases biológicas da compreensão humana. São Paulo: Palas Atenas, 2001. 
MESQUITA, R. et al . Análise de redes sociais informais: aplicação na realidade da escola inclusiva. Interface (Botucatu), Botucatu, v. 12, n. 26,set. 2008 . Disponível em

$<$ http://www.scielo.br/scielo.php?script=sci_arttext\&pid=S1414-

$32832008000300008 \& \operatorname{lng}=$ pt\&nrm=iso $>$. Acesso em 12 mai. 2009.

MOITA, F. M. G. da S. C. Games: Contexto Cultural e Curricular Juvenil. 2006. $181 \mathrm{f}$.

Dissertação (Mestrado em Educação). Universidade Federal da Paraíba, 2006.

MORRISH, I. Sociologia da educação: uma introdução. Trad. Álvaro Cabral. 2. ed. Rio de Janeiro: Zahar, 1975.

NEVES, F. F. R.; LEITE, I. A.; BRAMBILLA, M. A.; ACCARDO, R. P. In: CONGRESSO BRASILEIRO DE CIÊNCIAS DA COMUNICAÇÃO, 30., 2007, Santos. Anais. Disponível em: <http://www.intercom.org.br/papers/nacionais/2007/resumos/R2412-1.pdf>. Acesso em: 24 mar. 2009.

NONAKA, I.; TAKEUCHI, H.; Criação de conhecimento na empresa: Como as empresas japonesas geram a dinâmica da inovação. Rio de Janeiro: Campus, 1997. tradução Ana Thorell. Gestão do Conhecimento. Porto Alegre: Boockman, 2008.

PIAGET, J. Psicologia e pedagogia. Trad. Dirceu Accioly Lindoso e Rosa Maria Ribeiro da Silva. 7.ed. Rio de Janeiro: Forense Universitária, 1985.

PRETTO, N.; PINTO, C. C. Tecnologias e novas educações. Rev. Bras. Educ., Rio de Janeiro, v. 11, n. 31,abr. 2006 . Disponível em

$<$ http://www.scielo.br/scielo.php?script=sci_arttext\&pid=S1413-

$24782006000100003 \& \operatorname{lng}=$ pt\&nrm=iso $>$. Acesso em 28 abr. 2009.

SANCHO, J. M. (org.). Para uma Tecnologia Educacional. Porto Alegre: ArtMed, 1998. Tecnologias para Transformar a Educação. Porto Alegre: ArtMed, 2006.

SCHMID, B.; Stanoevska-Slabeva, K.; Knowledge Media: An Innovative Concept and Technology for Knowledge Management in the Information Age. 1998. - Beyond Convergence, 12th Biennal International Telecommunications Society Conference. Stockholm, Sweden. - Volltext unter. Disponível em $<$ http://www.alexandria.unisg.ch/Publikationen/9455> Acesso em 31/10/2009.

SQUIRE, K. Video Games in Education. International Journal of Intelligent. Simulations and Gaming, 2003.

Changing the Game: What Happens When Video Games Enter the Classroom?

Disponível em:

$<$ http://www.innovateonline.info/index.php?view=article\&id=82\&action=article $>$ Acesso em: 08/11/2010.

SVEIBY, K. A Nova Riqueza das Organizações. Rio de Janeiro: Campus. 1998. Apud FIALHO \& CARVALHO. 2005. 